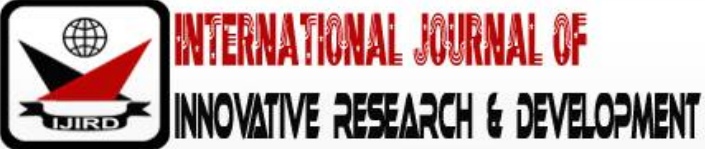

ISSN 2278 - 0211 (Online)

\section{Suicidal Ideation among Undergraduates in Nigeria: The Predictive Role of Personality Traits and Academic Stress}

\begin{tabular}{|c|}
\hline Onu Sonia \\
Postgraduate Student, Department of Psychology, \\
Nnamdi Azikiwe University, Awka, Nigeria \\
Okoye Chukwuemeka F.A. \\
Senior Lecturer, Department of Psychology, \\
Nnamdi Azikiwe University, Awka, Nigeria \\
Mabia Chidozie \\
Lecturer, Department of Psychology, \\
Nnamdi Azikiwe University, Awka, Nigeria \\
Ifedigbo Chinenyenwa .F \\
Postgraduate Student, Department of Psychology, \\
Nnamdi Azikiwe University, Awka, Nigeria \\
Babatunda, Stephen .I \\
Postgraduate Student, Department of Psychology, \\
Obafemi Awolowo University, Ile Ife, Nigeria
\end{tabular}

\begin{abstract}
:
In recent times, the life challenges experienced by individuals are becoming increasingly enormous due to changes in the dynamics of the society and life circumstances. Thus, suicide is sought by some individuals as a way of escaping from their unbearable life challenges. This study examined the predictive effect of personality traits and academic stress on suicidal ideation among undergraduates in Nnamdi Azikiwe University Awka. A sample of 203 participants were selected using the multi-stage sampling technique. The ages of the participants ranged from 18yeaars to 29years, with a mean age of 22.53 and standard deviation of 2.33. Three instruments namely the Big-Five Personality Inventory by John, Donalue and Kentle (1991), student Academic Stress Scale by Busari (2011) and Suicidal Ideation Attributes Scale by Spikker, Batterham, Calear, Farrer, Christensen, Reynolds and Kerkhof, (2011) were used for data collection. The Multiple Regression was employed to test the predictive effect of personality on suicidal ideation, while a simple Linear Regression was used to test the predictive effect of academic stress on suicidal ideation at 0.05 level of significance. The findings of the study indicated that personality traits did not have any statistically significant predictive effect on suicidal ideation. Also, academic stress was found to have no statistically significant predictive strength on suicidal ideation. Based on these findings, the researchers recommended that further studies should focus on other variables such as social background, family relations and other demographic variables, since suicide is a psychosocial/health problem in Nigeria.
\end{abstract}

Keywords: Suicidal ideation, personality traits, and academic stress

\section{Introduction}

Suicide has been reported in advanced counties as the number two cause of death among individuals between the ages of 18 to 35 (NOCK, 2008). In the United States, suicide ideation and attempts among adolescents have been reported as being increasingly recognized as important public health problem (Stone, 2015).

Although, suicide attempts and its thoughts are considered as taboo in Nigeria, there have been reported cases of suicide on the newspapers and social media. For example, a medical doctor was reported to have jumped into the Lagos mainland bridge Lagoon in March, 2017 (Muanya \& Ezea, 2017) shortly after that, a 500-level urban and Regional Planning student of Ladoke Akintola University of Technology, Ogbomosho hung himself from his ceiling fan while his roommate was out. Another student of Babcock University, Ogun State, who was just 19 years old at the time of his death, committed suicide in his parents' home at Lagos (Ezeobi, 2017).

According to Vanguard Newspaper on the 6th April 2019, a lecturer at the Department of Mathematics in University of Ibadan ended his life through suicide as a result of frustration of unfulfillment Ph.D programme. 
Also, there was another report of a 100-level student of Kogi State University, Ayingba who committed suicide after she was reportedly abandoned by her boyfriend. In 2019 alone, reported cases of suicide death was very rampant in national dailies and other media outfits.

Ogbolu (2019) reported that suicide accounts for 1.5 percent of global deaths and that suicide ranks among the top 20 leading causes of death. He also noted that 78 percent of suicides occur in low- and middle-income countries like Nigeria. Furthermore, Purse (2019) stated that suicide is common among women, with 5.1 percent than men 3.6 percent globally. Indeed, women attempt suicide more than men, but men are successful about three or four times more often than women.

These cases go on and on; Just in March, 2017 alone, over five different cases of either completed suicide or attempted suicide were reported in the newspapers. Indeed, different people face different life challenges at different times in their lives. While some survive from these challenges; others contemplate suicide as a way of escape. The question therefore is what makes individual including students consider or contemplate suicide?

Within the context of university students, challenges often manifest in forms of conflicts with girlfriend/boyfriends, selfdestructive peer acceptance, bullying and victimization, disappointment with school results and failure in studies, high demands at school during examination periods among others; which pose a lot of stress to students to the extent that the thought of suicide is often considered.

In essence, Cole, Protinsky and Cross (2005), defined suicide as the complete process of a continuum that began with suicide ideation, followed by an attempt at suicide, and finally completed suicide. This means that every suicide attempt or completed suicide often starts with suicidal thoughts (Roberts, 2008), and this is captured in the concept of suicidal ideation.

Consequently, suicidal ideation refers to thoughts about suicide, which may be deliberately constructed to fail or be discovered, or may be fully intended to succeed (Aqeel, Mohamed, Abdul \& Roslee, 2014).

Robert (2008) also saw suicidal ideation as a concept that includes all overt suicidal behaviours and communications such as suicide threats and expressions of wish to die. Furthermore, according to Shittu, Alabi, Odeigah, Musa, Sanni, Issa, Olanrenaju, Sule and Aderihigbe, (2014) suicidal ideation is the thought about or an unusual preoccupation with suicide.

A major concern among academic scholars about suicidal ideation has been to identify the prevailing factors that are associated with suicidal ideation. Thus, within the ambit of extant academic literature, reveals that certain variables such as hopelessness, academic failure, depression, poor social support system, death of a loved one, emotional trauma, serious physical illness, aging, unemployment, financial problems, guilt feeling, dependence on alcohol or other drugs are associated with suicidal ideation (Hudgens, 2003).

Among these variables, personality traits and academic stress have been found to significantly predict suicidal ideation, especially within the academic context (Zhang, Wang, Xia, Liu \& Jung, 2012; /Allred \& Hogstromthe, 2013; Venumadhava \& Mayuri, 2014; Shim and Jeong, 2018).

Personality traits relates to inherent behavioural qualities which are unique in every individual. According to Larsen and Buss (2002), personality traits represents behavioural traits and mechanisms within individuals that are organized and relatively enduring and that influence their interaction with others and adaptations to the environment including the inter-psychic, physical and social environment.

The above view was also supported by Robin (2003), who defined personality traits as the combination of different psychological traits of an individual which include extraversion, agreeableness, conscientiousness, neuroticism and openness to experience. Thus, the reaction to stressful academic tasks among students may vary based on their personality traits.

Academic stress on the other hand, refers to the negative emotional cognitive, behavioural and physiological conditions that occur as students try to adjust or deal with demanding academic tasks in the academic environment. Among undergraduates, academic stress may arise from both academic and non-academic sources, including sociocultural, environmental, and psychological attributes (Brand \& Schoonheim, 2009).

Indeed, several theories have been propounded by academic scholars to explain the aetiology and causes of suicidal ideation. They include: The three- step theory (Klonsky and May, 2014). Big Five Personality theory (Goldberg, 1992); and the Strain theory (Menton, 1998).

The three-step theory of suicidal ideation as propounded by Klonsky and May (2014) was of the view that the first step towards ideation begins with pain. They argued that individuals perform behaviours that are rewarded and avoid behaviours that are punished. Hence, if an individual constantly experience pain in his or her day-to-day living, such individual is constantly being punished for living; which may decrease the desire to live and in turn, initiate thoughts about suicide. They also believe that different sources of pain can lead to decreased desire to live. Verochio, Carrozzino and Bech (2016), indicated that negative emotions such as guilt, shame and hopelessness may become generalized experience of unbearable mental pain especially when there is no foreseeable change in the future, hence individuals may seek escape through dying by suicide.

Another theory, the Big Five Personality theory was based on the premise that no two individuals have the same personality make-up and within this premise established five major individual patterns of psycho-social behaviours within their environments. In other words, the Big Five Personality traits as established by Goldberg (1992) are enduring characteristics that dominate human existence, of which each individual displays a characteristic trait that prevails throughout his life. These traits include extraversion (social, active, assertive, energetic and talkative); Agreeableness (appreciative, generous, kind, sympathetic, forgiving and trusting); Conscientiousness (efficiency, organization, reliability, 
responsibility, thoroughness, self-discipline and dutifulness), Neuroticism (self-pity, tense, touchy, unstable and worrying) and openness to experience (adventurous, creative).

Furthermore, the strain theory was propounded by Merton (1938). In this study, the general strain theory as posited by

Agnew (1992) was adopted. Agnew (1992) advanced this theory to explain crime and deviance; and later suicidal ideation. He argued that strain can come from forces other than economic failure and identified three sources of strain namely: (1) Strain as the actual or anticipated failure to achieve positively valued goals (e.g. failing on examination), (2) Strain as the actual or anticipated removal of positively valued stimuli (e.g. losing a job), and (3) Strain as the actual or anticipated presentation of negatively valued stimuli (e.g. being treated poorly by others). These strains are important because they lead to the development of negative emotions, or as Agnew described them "negative affective states". In line with the argument of Agnew (1992), Strains like negative relations with family, school experiences that include low grade, negative relations with teachers, peer rejection, and so on, can lead to suicidal behaviour.

In the same vein, several empirical studies were reviewed to explain the predictive relationship between the predictor variables and the criterion variable. In a study by Abdollah, Ali, Khodabakhsh, Hediye, Alireza and Motahave (2014), on the personality factors underlying suicidal behaviour, among military youths using a sample of 1659 participants, revealed that a significant negative correlation existed between extraversion, agreeableness, conscientiousness and suicidal ideation.

Also, Devi and Prakash (2015), used the revised NEO-Five Personality Inventory and Adult Suicidal Ideation Questionnaire to investigate the relationship between personality traits and suicidal ideation among 100 college students and found that low extraversion and low conscientiousness have positive relation with suicidal ideation. The study also showed that openness to experience and agreeableness have insignificant relation with suicidal ideation.

Segal, Marty, Meyer, and Coolidge (2012), conducted a study on personality, suicidal ideation and reasons for living among older adults in Colorado. The participants were 109 older adults recruited through a newspaper advertisement. The result showed that personality traits had negative correlations with suicidal ideation, expect for neuroticism which has a positive correlation.

In another study by Shittu, Alabi, Odeigah, Sanni, Issa, Olanrewaju, Sule and Aderibigbe (2014), a hospital-based cross-sectional descriptive study on suicidal ideation among 170 depressed adult patients living with HIV/AIDS in Kwara State, Nigeria. The result showed that $16.5 \%$ of the participants reported having suicidal ideation, while $3.5 \%$ had plans in place on how to take their lives. However, the important finding of the study is that the patients with higher scores in depression and hopelessness (attributes of neuroticism) were found to be higher in suicide ideation.

Brezo, Paris, Tremblay and Vitaro (2015) conducted a study on personality traits as correlates of suicide attempts and suicidal ideation in young adults, involving 1140 participants. The findings showed that personality traits of conduct and identity problems such as neuroticism contributed to higher odds of both suicide attempts and suicidal ideation.

Raynolds (2015), examined perceived stress and suicidal behaviour in college students, involving 913 residential college students remitted from a rural south-eastern University. The findings showed that perceived academic stress significantly correlated with suicidal behaviour.

Khan, Mustaffa, Hamdan and Ahmad (2014), interrogated psychological factors that influence suicidal ideation among adolescents in Malaysia and India. The participants were 204 Malaysian students (63 males and 141 females) and 200 Indian students (100 males and 100 females) aged from 15-21 years. The result showed that Indian students were significantly higher in suicidal ideation, than the Malaysians.

In a study by Wang and Miao (2009), it was found that neuroticism and psychoticism were linked to immature coping styles, such as self-blame, fantasizing and avoidance, which ultimately have higher odds of suicide ideation.

Also, Chioqueta and Stiles (2011) in their study found that neuroticism personality dimension is associated with negative emotions like depression and depression is considered a risk factor for suicide. Also, neuroticism is associated with depression, anger, hostility, impulsivity and vulnerability. These factors in addition to being directly involved in suicide ideation, predispose the individual to suicide tendencies through creating despair. Despair as a risk factor for suicide is positively correlated with neuroticism and negatively correlated with extraversion.

\subsection{Statement of the Problem}

Suicidal ideation is an important concept in clinical and social psychology. This is because studies have noted that there is high rate of suicide cases, especially in the developing world (Venumadhava and Sahay 2014).

In Nigeria suicide cases have also escalated among the populace, including the student population. Popescu (2014), posited that this alarming rate has been associated with high level of academic stress within the university environment. Despite how important it is to understand and explain issues associated with suicidal ideation, unfortunately, there are not much empirical studies conducted in Nigeria in this area. Thus, what informs suicidal ideation among university students, especially in Nigeria remains probable. Meanwhile, few observed cases of suicide have been linked to stress compiled with personality traits (Allred, Granger \& Hogstromthe, 2013).

\subsection{Research Questions}

- Would personality traits (agreeableness, conscientiousness, extraversion, neuroticism, openness to experience) predict suicidal ideation among university undergraduates?

- Would academic stress predict suicidal ideation among undergraduates? 


\subsection{Purpose of the Study}

The major purpose of the study was to examine personality traits and academic stress as predictors of suicidal ideation among undergraduates. Specifically, the objectives were:

- $\quad$ To examine whether personality traits will predict suicidal ideation among undergraduates.

- $\quad$ To examine whether academic stress will predict suicidal ideation among undergraduates.

\subsection{Hypotheses}

- $\quad$ Personality traits will significantly predict suicidal ideation among undergraduates.

- Academic stress will significantly predict suicidal ideation among undergraduates.

\section{Method}

\subsection{Participants}

Two hundred and three (203) undergraduate students of Nnamdi Azikiwe Students participated in the study. They were sampled from Five Faculties and subsequently five departments through a Multi-Stage Sampling Technique, and Simple Random Sampling Technique. The ages of the participants ranged from 18-29 years, with a mean age of $22.53 \%$ and standard deviation of $2.33 \%$.

\subsection{Instruments}

The three instruments used for data collection were the Big-Five Personality Inventory developed by John, Donahue and Kentle (1991), Student Academic Stress Scale (SASS) developed by Basari (2011), and Suicidal Ideation Attribute Scale (SIDAS) developed by Spijker, Batterham, Calear, Farrer, Christensen, Raynolds and Keerkhof (2011). The reliability and validity of the instruments were ascertained accordingly.

\subsection{Procedure}

The researchers administered the instruments to the participants in their respective departments before lectures. The participants were instructed on the content and purpose of the study. After filling the instruments, they were immediately retrieved for further analysis. Out of the 203 questionnaires that were administered, 200 were properly filled, and were selected.

\subsection{Design and Statistics}

The study was a predictive survey design. The multiple Regression Statistics was used to test the hypotheses.

\section{Result}

\begin{tabular}{|c|c|c|}
\hline & MEAN & SD \\
\hline Age & 1.52 & .58 \\
\hline Gender & 1.40 & .49 \\
\hline Extraversion & 24.48 & 4.09 \\
\hline Agreeableness & 32.76 & 4.34 \\
\hline Neuroticism & 22.52 & 4.98 \\
\hline Conscientiousness & 32.10 & 4.57 \\
\hline Openness to Experience & 35.98 & 5.02 \\
\hline Academic Stress & 49.78 & 10.83 \\
\hline Suicidal Ideation & 11.10 & 5.86 \\
\hline
\end{tabular}

\begin{tabular}{|c|c|c|c|c|}
\hline Personality Traits & $\mathbf{R}^{2}$ & $\begin{array}{c}\text { Standardized } \\
\text { Coefficient }\end{array}$ & $\mathbf{t}$ & Sig \\
\hline $\begin{array}{c}\text { Personality traits } \\
\text { (General mode) }\end{array}$ & .026 & & 1.015 & .410 \\
\hline Extraversion & & .12 & 1.56 & .12 \\
\hline Agreeableness & & -.03 & -.32 & .76 \\
\hline Neuroticism & & -.06 & -.76 & .45 \\
\hline Conscientiousness & & .04 & .436 & .66 \\
\hline Openness to Experience & & -.11 & -1.25 & .21 \\
\hline
\end{tabular}

Table 2: Summary Table of Multiple Linear Regressions Showing the Predictive Strength of Personality Trait on Suicidal Ideation

The result in the table indicated that the five subscales of the Big-Five statistically did not predict suicidal ideation, $\mathrm{F}(5,192)=1.015, \mathrm{P}>.05, \mathrm{R}^{2}=.026$. Thus, the hypothesis which stated that personality traits would predict suicidal ideation was rejected. 
Further test on the predictive effect of individual sub-scales of personality traits indicated that none of the subscales yielded a statistically significant predictive effect on suicidal ideation. In other words, suicidal ideation is not significantly predicted by extraversion, $F(5,192)=1.56, P>.05$, agreeableness, $F(5,192)=.-32, P>.05$; Neuroticism, $\mathrm{F}(5,192)=-.76, \mathrm{P}>.05$, conscientiousness, $\mathrm{F}(5,192)=.436, \mathrm{P}>.05$, and openness to experience, $\mathrm{F}(5,192)=-1.25, \mathrm{P}>.05$.

\begin{tabular}{|c|c|c|c|}
\hline Model & Standard Coefficient Beta & T & Sig \\
\hline 1 Constant & & 6.092 & .000 \\
\hline Academic Stress & & -.457 & .648 \\
\hline
\end{tabular}

Table 3: Summary of Regression Showing the Predictive Effect of Academic Stress on Suicidal Ideation

The result in the table showed that Suicidal Ideation was not significantly predicted by academic stress, F $(1,196)$ $=-.457, \mathrm{P}<.05$. Thus, the hypothesis which stated that academic stress could predict Suicidal Ideation was rejected.

\section{Discussion and Conclusion}

The first hypothesis which stated that personality Traits (agreeableness, conscientiousness, extraversion, neuroticism, openness to experience) would significantly predict suicidal ideation among undergraduates was rejected. The result showed that none of the personality traits had a significant predictive strength toward suicidal ideation. This finding was not in agreement with the findings of Wang and Miao, (2009) which showed that neuroticism significantly predicted suicidal ideation. Also, the present result is not in tandem with the findings of Chioqueta and Stiles (2011) who observed that neuroticism had a positive correlation with suicidal ideation and psychotic tendencies. They also found that extraversion had a negative correlation with suicidal ideation, which is partially in line with the present finding. In the same vein, Segal Marty, Meyer and Coolidge (2012) arrived at a result that slightly agreed with the findings of the present study, where they found that personality traits had negative correlation with suicidal ideation except for neuroticism which had a positive correlation with suicidal ideation. In the researcher's opinion, the findings were not surprising because of the secrecy with which cases of suicide are shrouded in Nigeria.

The disparity between the findings of the present study and the others before this could be attributed to the sensitive nature of suicide in Nigeria, where the undergraduates are not freely open to report that they ever contemplated killing themselves due to the stigma attached to the issue of suicide. In South Eastern States of Nigeria for instance, various cultures and communities frown at suicide and suicide related cases. Also, families and relations of suicide victims are stigmatized.

The second hypothesis which stated that there will be a significant relationship between academic stress and suicide ideation among undergraduates was also rejected. It therefore implies that despite the level of academic stress experiences by students, suicidal ideation is not often contemplated by a majority of the undergraduates. Again, this may be associated with high degree of obscenity and taboo attached to suicide within communities and cultures in the area where the study was carried out. This is not consistent with other research findings which suggested that high level of academic stress has a significant relationship with suicidal ideation (Zhang, Wang, Xia, Liu \& Jung, 2012).

Based on the findings of this study, the following recommendations were made:

- Since there was low prevalence of suicidal ideation among the students, effort should be intensified to maintain the tempo through public information and education on suicide.

- Government should also provide suicide counselling personnel who will always be available to offer assistance to those in need. A body for coordinating efforts on suicide prevention should be formed in the society/universities.

- Specific university-based mental health services should be established in various universities in Nigeria.

\section{Conclusion}

In conclusion, the result of the study showed that personality traits did not significantly predict suicide ideation, therefore rejecting the first hypothesis. Furthermore, the findings also revealed that academic stress did not significantly predict suicidal ideation among undergraduates who participated in this study; therefore, rejecting the second hypothesis. This implies that personality traits and academic stress are not predictors of suicidal ideation among undergraduates in Nigeria.

\section{References}

i. Abdollah, s; Ali, F; Khodabakhsh, A; Hediye, S. M; Alireza, N; \& Pilevarzadeh, M (2014). Personality Factors underlying suicidal behaviour among military youth. d Iran Red Crescent Medical Journal, 16(4):126-132.

ii. Agnew, R. (1992). Synnomie to Anomie: A macro sociological Formulation. The Legacy of anomie theory. Advances in Criminology Theory, 6(1): 271-83.

iii. Allred, A; Granger, M; \& Hogstromthe, T. (2013). The relationship between academic mayou, personality type and stress in college students. Eukaryon, 9, Lake Forest College.

iv. Aqeel, K; Mohamed, S.M; Abdul, R.H. \& Roslee, A. (2014). Influence of psychological factors on suicide ideation among Malaysian and Indian adolescents. Social and Behavioural Science, 143; 341-351.

v. Brand, H; \& Sehoonheim-Klein, M. (2009). Is the OSCE more stressful? Examination anxiety and its consequences in different assessment methods in dental education. European Journal of Dental Education, 13: 147-153.

vi. Brezo, J; Paris, J; Tremblay, R; Vitaro, F; \& Hebert, M. (2015). Personality traits as correlates of suicide attempts and suicide ideation in young adults. Psychology of Medicine, 36(2):191-202. 
vii. Chioqueta, A. P; \& Stiles, T.C. (2011). The relationship between psychological buffers, hopelessness and suicidal ideation. Crisis, 28(2): 67-73.

viii. Cole, D. E; Protinsky, H. O; and Cross L. H. (2015). An Empirical Investigation of Adolescent Suicidal Ideation. Adolescence 27(108) 813-8.

ix. Devi, S.N \& Prakash, N.R. (2015). Life Skills Assessment Among Undergraduate Students. Scholarly Research Journal for Interdisciplinary Studies. (3),3127-3138.

x. Ezeobi, C. (2017). Rising cases of Suicide. This day newspaper. April 3, 2017. https://www.thisdaylive.com/index.php/2017/04/03/rising-cases-of-suicide.

xi. Goldberg, L. R. (1992). The development of marketers for the big five structure. Psychological Assessment, 4: 2642.

xii. John, O. P., Donahue, E.M., \& Kentle, R.L. (1991). Big Five Inventory-Versions 4a and 54 Berkeley: University of California Berkeley Institute of personality and social research.

xiii. Khana, A., Mustaffa, M.S., Hamdan, A. R; \& Ahmad, R. (2014). Influence of Psychological factors on suicide ideation Among Malaysian and Indian Adolescent. Procedia Social and Behavioural Sciences. 143, 347-351.

xiv. Klonsky, D.E; \& May, A.M. (2015). The three-step theory (3ST): A new theory of suicide rooted in the "ideation-toaction" framework. International Journal of cognitive therapy, 8(2): 114-129.

xv. Larson, R.J; \& Buss, D. M. (2005). Personality psychology: Domains of Knowledge about human nature (2nd ed.). Boston: McGraw-Hill.

xvi. Muanya, C; \& Ezea, S. (2017). Worrisome, rising cases of suicide in Nigeria. The Guardian newspaper. 25 March, 2017. http://guardianng/saturday-magazine/worrisome-rising-cases-of-suicide-in-nigeria/ampl.

xvii. Nock, M.K; Borges, G; Bromet, E.J; Cha, C.B; Kessler, R.C; \& Lee, S. (2008). Suicide and Suicide behaviour. Epidemiologic Reviews published by the Johns Hopkins Bloomberg School of Public Health, 30, $133,-154$.

xviii. $\quad$ Ogbolu, R.E. (2019), Nigeria Suicide Research and Prevention Initiative. Vanguard Newspaper, April 2019.

xix. Popescu, C.A. (2014). Personality factors associated with academic Stress in first year medical students. International Journal of the Bioflux Society, 6, 40-44.

xx. Purse, M. (2019). What is Suicide Ideation? Very well mind.

xxi. Raynolds, E. (2015). Perceived Stress and Suicidal behaviours in college students: Conditional indirect effects of depressive symptoms mental health stigma. Undergraduate Honours Thesis, Paper 284. http://dc.etsu.edu/honors/284

xxii. Roberts, R.E \& Chen, Y.W. (2000). Depressive Symptoms and Suicidal ideation among Mexico origin and Anglo adolescents. Journal of American Academy of Child and Adolescent Psychiatry, 34, 51-90.

xxiii. Robin, R.W. (2003). Measuring global self-esteem: construct validation of a single-item measure and the Rosenberg self-esteem scale. Personality and social psychology Bulletin, 27, 151-161.

xxiv. Segal, D. L; Marty, M.A; Meyer, W.J \& Coolidge, F.L. (2012). Personality, suicidal ideation, and reasons for living among older adults. The Journal of Gerontology Series B: Psychological Sciences and Social Sciences, 67(2), 159166.

xxv. Shittu, O.R; Alabi, K.M; Odeigah, L.O; Musa, A; Sanni, L.O; Issa, B.A; Olanrewaju, A.T; Sule, A.G; \& Aderibigbe, S.A. (2014). Suicidal ideation among depressed people living with HIV/AIDS in Nigeria, West Africa. Open Journal of Medical Psychology, 3,262-270.

xxvi. Shim, G; \& Jeong, B. (2018). Predicting suicidal ideation in college students with Mental health Screening Questionnaires. Psychiatry Investigation 15(11):1037-1045.

xxvii. Spijker, B.A.J; Batterham, P.J; Calear, A.L; Farrer, L; Christensen, H; Reynolds, J; \& Kerkhof, J.F.M. (2014). The suicidal Ideation Attributes Scale (SIDAS): Community-Based Validation study of a New Scale for the Measurement of Suicidal Ideation, 1-12.

xxviii. Stone, G.(2015). Suicide and attempted suicide. New York: Carol and Graf.

xxix. Venumadhava, G.S; \& Sahay, M. (2014). Academic stress and Suicidal tendency. Golden Research Thoughts Impact Factor, 3(11): 524-555.

xxx. Verrocchio, M.C; Carrozzino, D; \& Bech, P. (2016). Mental pain and suicide: A systematic Review of the literature. Journal of Medicine and Health, 7, 1-6.

xxxi. Wang, W; \& Miao, D. (2009). The Relationship among coping styles, Personality traits and mental health of Chinese medical students. Social Behaviour and Personality, 37(2): 163-172.

xxxii. Zhang, X; Wang, H; Xia, Y; Liu, X; \& Jung, E. (2012). Stress, Coping and Suicidal Ideation in Chinese College Students. Faculty Publication, Department of Child, Youth and Family Studies. Paper 79. http://digitalcommons.unl.edu/famconfacpub/79. 